\title{
1 Dimensions of continents and oceans - water has carved a perfect cistern
}

2 J. A. Whitehead

3 Department of Physical Oceanography,

4 Woods Hole Oceanographic Institution

5 Woods Hole, MA 02540 USA

$7 \quad 26$ March 2017

8 Earth and Planetary Science Letters, 467, 18-29. doi:10.1016/j.epsl.2017.03.017.

9 Abstract: The ocean basins have almost exactly the correct surface area and average

10 depth to hold Earth's water. This study asserts that three processes are responsible for

11 this. First, the crust is thickened by lateral compression from mountain formation.

12 Second, Earth's continental crust is leveled by erosion. Third, due to the efficiency of

13 erosion, the average elevation is a few hundred meters above sea level. A theoretical fluid

14 model, suggested partly by laboratory experiments, includes an ocean of specified depth.

15 The resulting continents are tabular (that is, their elevation view is rectangular). The

16 surface lies above sea level, contributing to a well-known double maximum in Earth's

17 elevation corresponding to continents and ocean basins. Next, a simple hydrostatic

18 balance between continent and ocean gives average depth and area of present oceans and

19 continents within $33 \%$. Further calculations with a suitable correction to fit present Earth

20 cover a wide range of possible crust volumes for earlier Earth. With the present water

21 volume, ocean area always exceeds $25 \%$ of the globe. For all possible water volumes,

22 average continental crust thickness always exceeds $23.4 \mathrm{~km}$. This may explain why

23 cratons have thicknesses comparable to younger crust so that they are found on Earth's

24 surface today. Therefore, mountain building, and erosion have enabled water to carve its

25 own cistern in the form of the accumulated ocean basins. The wide range of areas and

26 depths of oceans and continents found here can constrain models of early earth. Similar

27 calculations can be done for earthlike planets as well.

29 Keywords: freeboard, continental crust depth, ocean depth, continent area, ocean area,

30 continental crust and water volumes 


\section{Introduction}

It is well known that Earth's ocean basins average approximately $3800 \mathrm{~m}(2.5$ miles) depth covering approximately $70 \%$ of the surface and containing $97 \%$ of the world's water (e.g. Sverdrup et al. 1942). The deep ocean basins contain even closer to

$5 \quad 100 \%$ of Earth's liquid water during glacial periods. Therefore, continents and oceans have come to a balance so that the ocean basins hold almost all of the water. This chemical evolution and building of continental material (e. g. Dewey and Windley 1981,

11 McLennan and Taylor 1983, Cogley 1984, Taylor and McLennan 1995, Saal et al. 1998,

12 Clift and Vannuchi 2004, Hawkesworth et al. 2010, Walther 2005, O'Neill et al. 2015).

13 The mechanical consequences of orogeny, volcanism and sedimentation seem to be

14 studied less. How did the continents and ocean basins mechanically evolve so that the 15 oceans have exactly the correct area and average depth to hold Earth's water? However, 16 the overall dimensions of continents and oceans have their origin in the balances between 17 mountain building and erosion rate (Harrison 1994, Zhang 2005, et al., Roberts 2015).

18 Here, the freeboard concept (Wise 1972, 1974) is added as in Whitehead and Clift 2009, 19 which leads to mean continent elevation being only a few hundred meters above sea level.

Mountain building is a direct consequence of the great rigid "tectonic" plates

22 produced and moves away from mid-ocean ridges at divergent margins, and the floor is

23 consumed by sinking (subducting) into the interior of the earth (the mantle) in subduction

24 zones at convergent margins. Therefore, any fixed thing within a plate, including a

25 continent, migrates from divergent to convergent margins. Once a continent arrives at a

26 subduction zone, compression and orogeny occurs and mountain belts are produced

27 (Press 2003, Johnson and Harley 2012). Over 80 orogenic events exist in the geological

28 record over roughly four billion years (Kearey et al. 2009, Johnson and Harley 2012)

29 pointing to the possibility of plate tectonics existing over that period of time. Although

30 each event has a special story (e.g. Royden 1993a, Kaufman and Royden 1994, Huerta et

31 al. 1996, 1998, 1999, Thatcher et al. 1999, Yin and Harrison 2000), during each event, 
1 the continental crust is thickened. Orogeny produces a thickness increase of $2.5 \%$ in the

2 past 65 my (Clift and Vannuchi 2004, Whitehead and Clift 2009). The thickening

3 decreases the total continent area by $1.7 \%$ and consequentially increases ocean area.

4 This persistent crustal thickening is balanced to first order by redistribution of

5 continental material by erosion (Harrison 1994). The erosion rates are sufficiently great

6 to erode the continent surface down to an elevation close to sea level. Estimates of time

7 scales for erosion of mountain belts are a few hundred million years, [Veizer and Jansen

8 1985; Harrison 1994, Zhang 2005, Clift et al. 2009]. The average surface elevation is

9 presently only 835 meters above sea level, so earth has tabular continents that lead to the

10 well-known double maximum in elevation distribution (Sverdrup et al. 1942, Harrison

11 1988, 1990 1998, Harrison et al 1981, 1983, 1985). This distribution is not observed for

12 other rocky planets and moons (Uchupi and Emery 1993).

13 The eroded continental material deposited on the seafloor is ultimately buried at

14 subduction zones (Clift et al., 2009). This material feeds volcanism that produces new

15 continent material through andesitic lavas at continent margins. (Gazel et al. 2015). The

16 cycle of water into and out of the mantle is also involved in generating new continental

17 crust (Höning and Spohn 2016). Another contributor to continent area increase is internal

18 deformation, which is best documented as strongly localized divergence within

19 mountainous regions [Kaufman and Royden, 1994], [Huerta et al., 1998, 1999], [Royden,

20 1993b, Huerta et al., 1996], [Thatcher, et al., 1999], [Bird, 1979, Kay and Kay, 1993]

21 [Conrad and Molnar, 1997, Houseman and Molnar, 1997]. For example, calculations

22 based on measurements of Himalayan spreading and uplift have produced estimates of

23 the viscosity of the continental material [England and Molnar, 1997, Flesch et al., 2000].

24 There is no present estimate of continent divergence globally.

25 Finally, the freeboard effect notes that continent edges are almost exactly at sea

26 level as a consequence of erosion, which is more effective under air than under the ocean

27 surface (Wise 1972, 1974, Harrison, 1998, 1999, Hynes, 2001, McElroy and Wilkinson,

28 2005). This effect, plus the strength of erosion (loc. cit.) limits the average elevation of

29 the continents to under $1 \mathrm{~km}$ above the sea surface. 


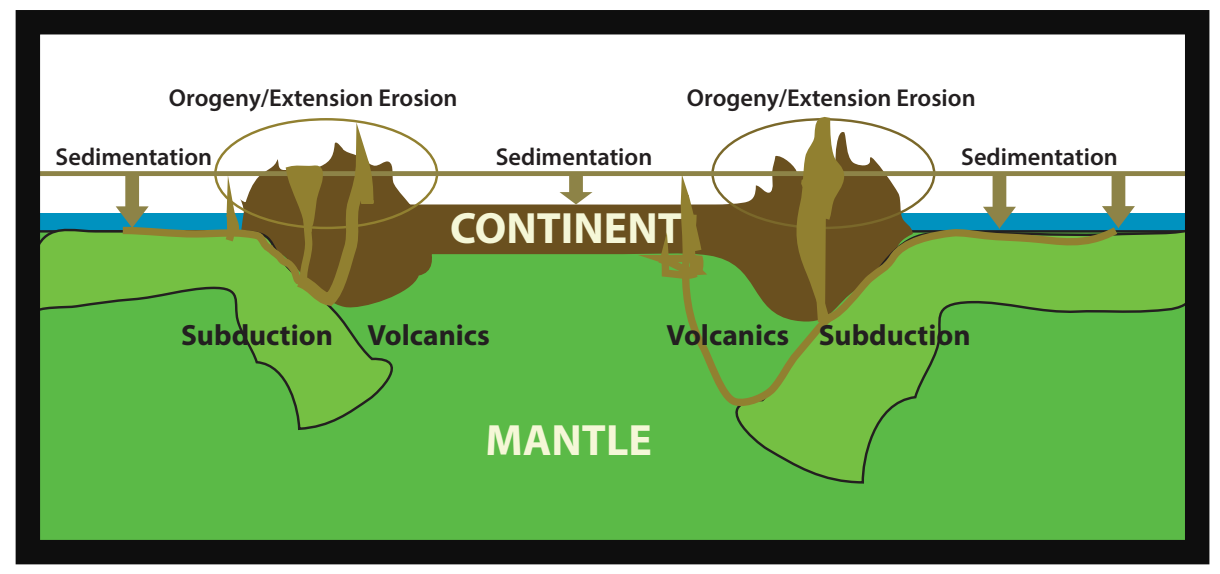

2 Figure 1. Processes altering the thickness and areas of continents and oceans to first order.

The balance between mountain building; continent extension; erosion;

5 sedimentation; the burial of sediments in the mantle; and the eventual return of some of

6 the sediment material and water to the continents is summarized in Figure 1. The purpose

7 of this paper is to present a simple fluid mechanical model of this and to report some

8 consequences of ensuing calculations. In Section 2, some fluid experiments show how

9 thickening of a floating fluid from convergence of an underlying fluid leads to elevation

10 of the surface. In Section 3, a fluid theory produces the tabular nature of continents when

11 the floating fluid is in the presence of an ocean. In Section 4, a simple calculation

12 explores a basic consequence of the constraint that continent elevation has a fixed value

13 above sea level. This simple isostatic calculation quantifies one of the fundamental

14 features of earth and oceans, yet it appears to be absent from textbooks and summarizing

15 articles about Earth (e. g. Schubert and Sandwell, 1989, Turcotte and Schubert 2002,

16 Press 2003, Grotzinger and Jordan 2010, King 2015, Condie 2016). Then, additional

17 calculations use other possible volumes of crust and water for an earlier Earth constraint. 


\section{2. Suggestive laboratory experiments}

3 Laboratory experiments were constructed to quantify the balance of crustal

4 thickening and spreading. The first experiment has a layer of high viscosity silicon oil

5 floating above corn syrup in a rectangular container (Figure 2). The roller on the right

6 rotates counterclockwise, and the one on the left rotates clockwise at the same rate.

7 Convergence at the oil-syrup interface driven by the two rollers thickens the center of the

8 layer of floating oil and elevates the surface (Figure 2b). For sufficient roller speed, the

9 oil separates from the walls (Figure 2c). Vertical thickening along the center of the tank

10 increases with roller speed (Figure 3). This agrees with a linear theory developed in the

11 Appendix. Using densities and viscosities of the laboratory materials, the maximum

12 elevation of the top surface $e$, (see the table in supplementary material for a list of

13 symbols) as a function of roller angular rotation rate $\Omega$, is given by the formula

$14 e=1.36 \times 10^{-3} \Omega$ and the depression of the interface $d_{i n}$ is given by $d_{i n}=3.31 \times 10^{-3} \Omega$

15 . Therefore, elevation is proportional to driving rate $\Omega$.

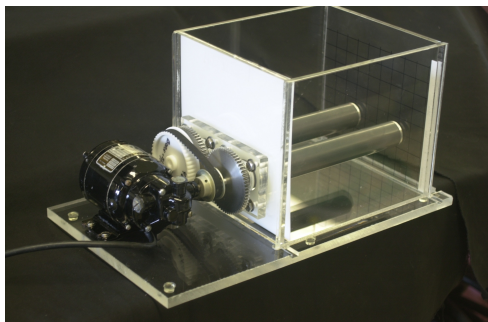

(a)

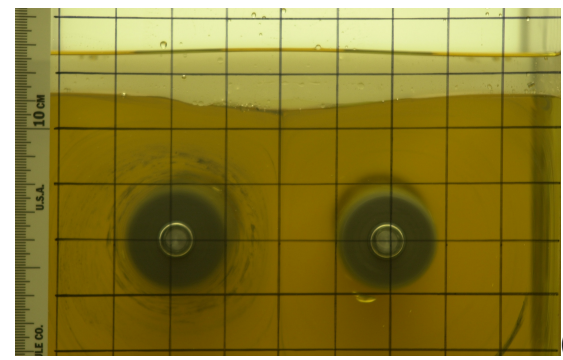

(b)

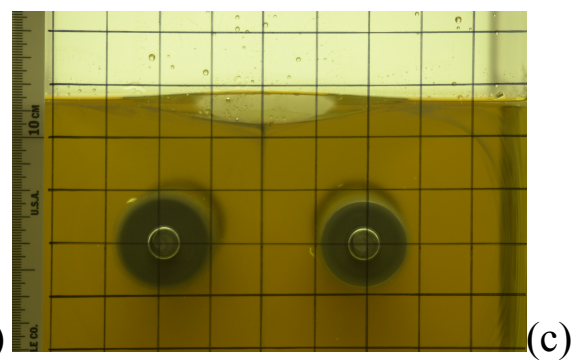

18 Figure 2. (a) The experimental apparatus with a flow driven by 2 rollers. This produces two overturning cells in the bottom fluid that exert stress to the upper fluid. (b) The top layer thickens at the center with upward deflection of the center for slow roller speed. (c) At higher roller speed, the surface layer is swept into an isolated body. 


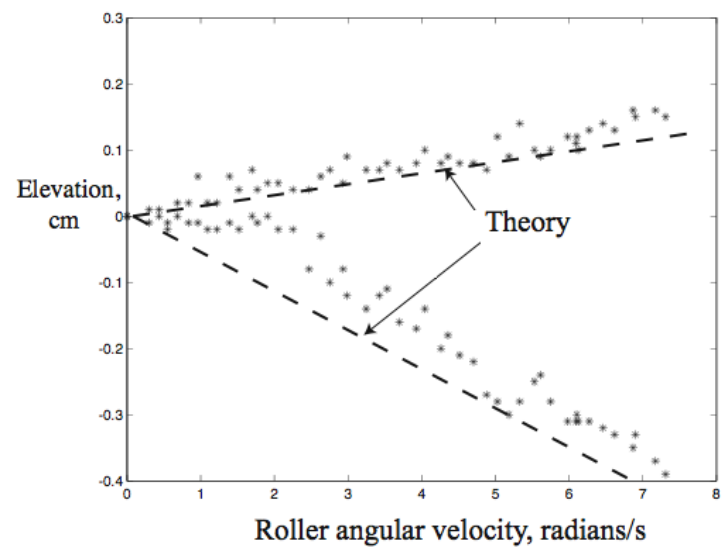

2 Figure 3. Elevation of the top and depression of the interface as a function of roller rotation rate

$\Omega$. The dashed lines are from equations (A20) and (A21) in.

The second experiment shows that the elevated surface is not dependent on

6 Newtonian viscosity. It has a top layer of 600 polypropylene balls of $0.64 \mathrm{~cm}$ diameter

7 combined with 100 balls of $0.32 \mathrm{~cm}$ diameter floating in silicon oil with kinematic

8 viscosity $10 \mathrm{~cm}^{2} \mathrm{~s}^{-1}$ lying under air. The combination of sizes of balls produces a mushy

9 matrix. They occupy half of the interior volume of a transparent circular cylinder whose

10 rotational axis is tangential to gravity. A circulation cell in the oil is driven by steady

11 slow counterclockwise rotation, sweeping the floating balls toward the descending region

12 on the left (Figure 4). There, the balls collect in a deep patch. The surface of the balls in

13 the patch lies above the level of the fluid, even though they are located above the

14 descending oil.

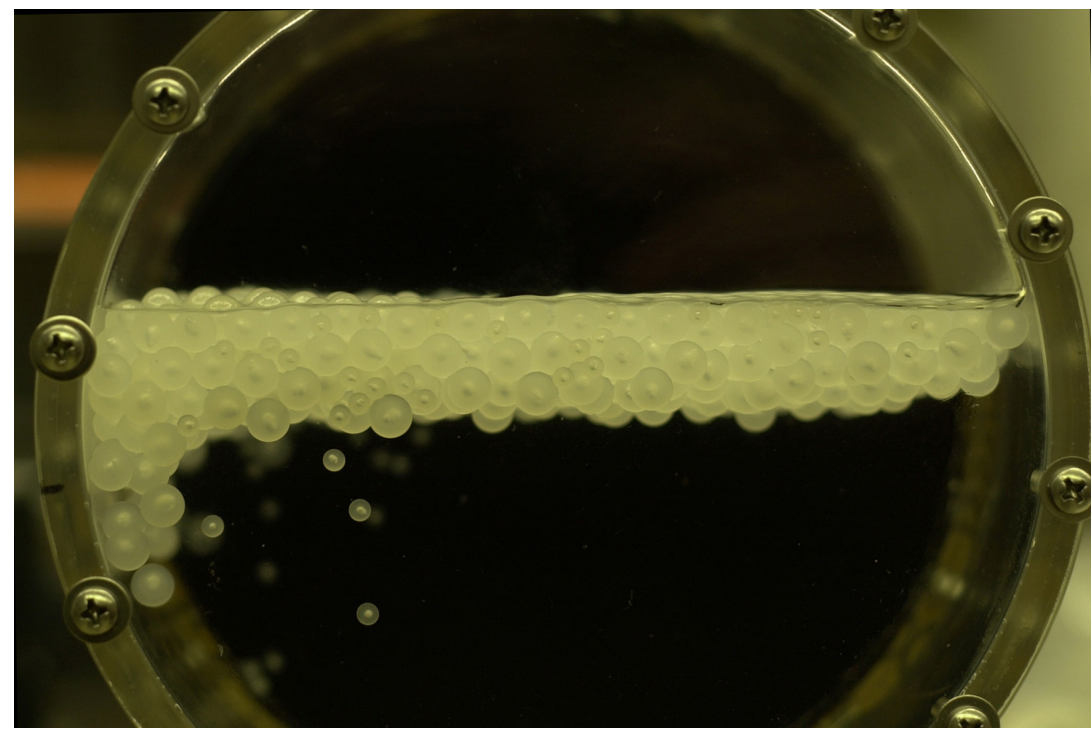


1 Figure 4. Photograph of a cluster of floating spheres in a counterclockwise slowly rotating cylinder $13.3 \mathrm{~cm}$ in diameter half full of silicon oil. The camera looks along both the axis of the cylinder and along the rotation axis. Gravity is directed downward.

5 All experiments show that the top surface of the thickened patch extends upward. The

6 elevation of the top layer in Figure 3 depends on the speed of the driving, so this

7 experiment does not include the two different rates of erosion under air and under water

8 that are vital to Wise's explanation of freeboard. Therefore, a simplified model and its

9 theory is developed that will incorporate the two different rates of flattening for continent

10 surfaces below and above water consistent with the freeboard concept.

\section{3. A mechanical model of a continent with the ocean present.}

This model has floating viscous fluid that is thickened by convergence from a

13 velocity imposed at the base of the continent material. To incorporate gravitational

14 spreading that balances this convergence, we take note of a popular parameterization for

15 erosion that flattens the continent surface in accordance with the relation

$16 \quad \frac{\partial h}{\partial t}=-K h$

18 Typically, the erosion rate $K$ is proportional to an erosion coefficient determined by the

19 land size, and inversely proportional to an erosion boundary layer depth and an isostatic

20 factor (e.g. Zhang 2005). In addition, $K$ typically is a nonlinear function of slope.

21 However, for simplicity our model makes $K$ a constant and we assign a viscosity to the

22 continent material, making it a Newtonian fluid.

23 Our model is a simplification of the dynamics of the continental crust (Figure 5a).

24 Flow at the base of the crust imposed by mantle flow pushes the deep continental

25 material toward the right (Figure 5a,b). The surface tilts upward toward the right to

26 provide a hydrostatic pressure gradient to drive the return flow. This is the exact balance

27 discussed by Zhang (2005), who parameterized erosion more fully than is to be done

28 here. Although earth has more than one continent, this model represents an average of all

29 the continents. 


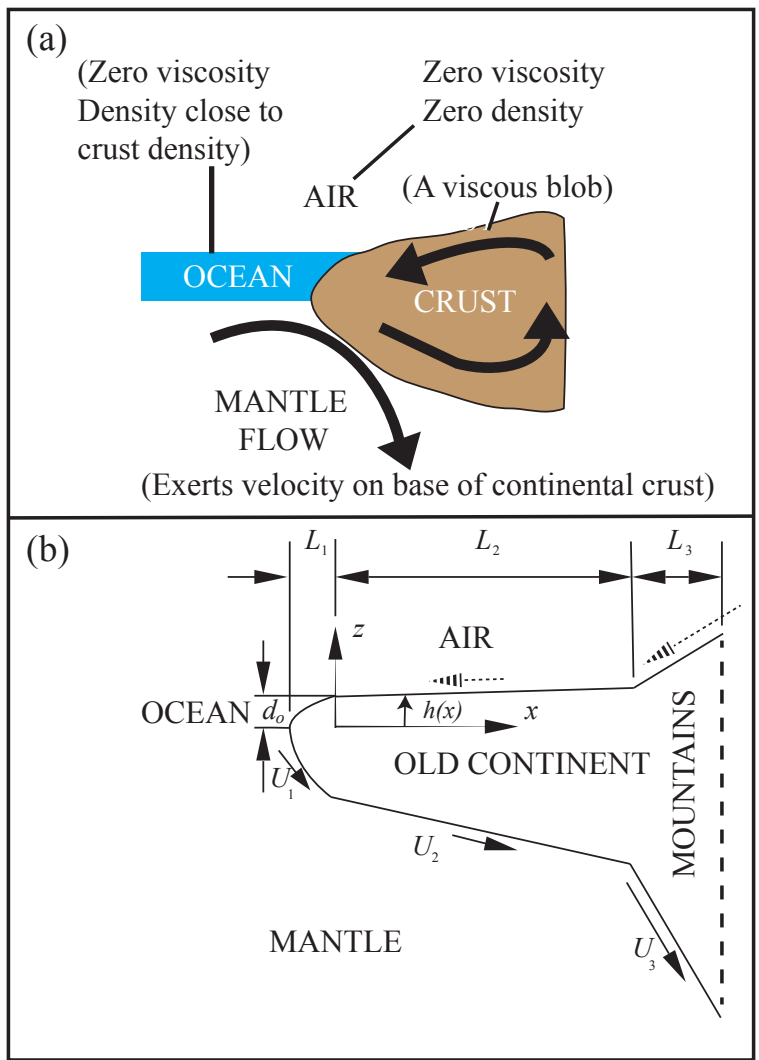

2 Figure 5. Elevation views of the simplified equilibrium state of the continents and oceans.

Vertical direction is stretched greatly. (a) A cartoon of the dynamics. Surface flow corresponding to erosion is generated by viscous flow within the continent, driven by bottom velocity. (b) Geometry of the theory. The surface flow shown by dashed arrows represents downhill movement of the surface through erosion.

In the mathematical model (Figure 5b), three fluids representing ocean, continent

9 and mantle have densities $\rho_{o}, \rho_{c}$, and $\rho_{m}$. They all lie in a field of gravity with

10 acceleration $g$ downward. Air lies over everything but it has negligible density and

11 viscosity. The ocean has depth $d_{0}$, and the continent has kinematic viscosity $v$. The

12 continent has three regions: 1 . The first is an old continent region under the ocean

13 surface. 2. This is an old continent region lying under air. 3. Finally there is a region of 14 mountains.

15 In all three regions, motion is imposed at the base of the continent by specifying

16 velocities. Regions 1 and 2 are characterized by different surface restoring forces as

17 models of erosion under water and under air, and they have a constant positive normal 
1 speed $U_{I}=U_{2}$. Region 3 has a greater normal speed $U_{3}$. This faster flow rate under

2 mountains represents convergence of the mantle in subduction zones that produce

3 mountain belts. The return flows are shown in Figure $5 \mathrm{~b}$ by dashed arrows. Return flows

4 are meant to represent and to simulate erosion and not actual creep of the continent

5 material. Slope is largest in Region 1 from a smaller restoring force that represents small

6 erosion rate. Regions 2 and 3 are characterized with two different bottom speeds.

7 Therefore, the mountains have a greater return flow in a negative direction than the return

8 flow of old continent under air. This is represented by the dashed arrow under $L_{3}$.

9 Surface slope is smallest in region 2.

The continent thickness and surface slope are calculated as a function of the ocean

12 depth, velocities, and physical properties of the materials. It will be assumed that the

13 aspect ratio $d_{0} / L_{2}$ is small. Although the speeds are free to vary over wide ranges of

14 possible relevance to Earth, Stokes flow is anticipated. This limit is defined using the

15 speed under region 2 as a typical speed so that $U_{2} d_{0} / v \ll 1$. To model the weak erosion

16 rate of the continent surface under water compared to erosion rate of the continent surface

17 under the atmosphere, we specify $\rho_{2}-\rho_{1} \ll \rho_{2}$. In other words, this model uses a small

18 surface restoring force to represent small erosion under the ocean. Thus, the density of

19 ordinary water is not used but instead a density close to continent density is given for the

20 ocean. This small density difference is an artifice to insure that the surface restoring

21 force of the continent under water is much less than the surface restoring force to the

22 continent under air.

23 In this model, the flow within the continent is the only unknown flow. The

24 continent fluid obeys continuity and Stokes flow.

$26 \nabla \cdot \tilde{u}_{i}=0$

$27 \nabla p_{i}=\mu \nabla^{2} \tilde{u}_{i}-g \rho_{c} \hat{k}$

28 with $\tilde{u}_{i}$ the velocity vector and $p_{i}$ the pressure. The ocean and atmosphere are low in

29 viscosity compared to the continent, producing negligible stresses on the continent except

30 for hydrostatics. In addition, atmospheric pressure is zero at sea level and along the 
1 continent surface. Third, the flow is strictly two dimensional in the vertical and lateral 2 plane.

3 The vertical origin is located at the ocean floor (Figure 5), and the lateral origin is

4 located at the continent-sea surface point of intersection. Taking the $\operatorname{limit} d_{0}^{2} / L_{2}^{2} \ll 1$,

5 (with $L_{2}$ a typical lateral length), the common lubrication approximation exists with

6 negligible vertical velocities and lateral derivatives. The hydrostatic equation governs

7 vertical forces for the continents.

8 We first develop the equations in the regions under air, (Regions 2 and 3) The

9 pressure obeys $p_{i}=0$ at $z=h_{i}(x)(i=2,3)$, where $h_{i}$ is the surface elevation above the ocean

10 floor. The hydrostatic approximation is

$11 \quad p_{i}=g \rho_{c}\left(h_{i}-z\right)$

12 Therefore, the lubrication approximation is valid in the lateral direction, and since it has

13 only vertical derivatives, the equation in each region is

$14 \frac{1}{\rho_{c}} \frac{\partial p_{i}}{\partial x}=g \frac{\partial h_{i}}{\partial x}=v \frac{\partial^{2} u_{i}}{\partial z^{2}}$

15 with solution

$16 \quad u_{i}=\frac{g}{v} \frac{\partial h_{i}}{\partial x} \frac{z^{2}}{2}+A_{i} z+B_{i}$

17 This approach resembles simple lubrication theory as applied for example for

18 asthenospheric flow and return flow (Turcotte and Schubert 2002). The depth of the base

19 of the continent is determined by setting pressure below it to the hydrostatic value using

20 the hydrostatic approximation,

$21 z=\delta h_{i}(x)$

22 where $\delta=\rho_{c} /\left(\rho_{m}-\rho_{c}\right)$. We set $u_{i}=U_{i}$ there to get

$23 \quad B_{i}=U_{i}-\frac{g}{v} \frac{\partial h_{i}}{\partial x} \frac{z^{2}}{2}+A_{i} \delta h_{i}$.

24 In addition, the lateral shear at the continent surface is set to zero giving 
$1 \quad A_{i}=-\frac{g}{v} \frac{\partial h_{i}}{\partial x} h_{i}$

2 Inserting these in (6),

$3 \quad u_{i}=\frac{g}{v} \frac{\partial h_{i}}{\partial x}\left(\frac{1}{2}\left(z^{2}-\delta^{2} h_{i}^{2}\right)-h_{i}\left(z+\delta h_{i}\right)\right)+U_{i}$.

4 Lateral volume flux $F_{i}$ is

$5 \quad F_{i}=\int_{-\delta h_{i}}^{h_{i}} u_{i} d z=-\frac{1}{3} \frac{g}{v} \frac{\partial h_{i}}{\partial x}(1+\delta)^{3} h_{i}^{3}+U_{i}(1+\delta) h_{i}$.

6 Steady State

7 For a continent that is steady and fully developed, $F_{i}=0$ so that

$8 \quad \frac{\partial h_{i}}{\partial x}=\frac{3 v U_{i}}{g h_{i}^{2}(1+\delta)^{2}}$.

9 This integrates to

$10 \quad h_{i}^{3}=\frac{9 v U_{i} x}{g(1+\delta)^{2}}+C_{i}$.

11 In region $2, h=0$ at $x=0$ so $C_{2}=d_{0}^{3}$ and the elevation is

$12 \quad h_{2}^{3}=d_{0}^{3}+\frac{9 v U_{2} x}{g(1+\delta)^{2}}$.

13 In region 3, the integration starts from the point where the surfaces are matched at $x=L_{2}$ so

14 the elevation is

$15 \quad h_{3}^{3}=d_{0}^{3}+\frac{9 v U_{3} x}{g(1+\delta)^{2}}+\frac{\left(U_{2}-U_{3}\right) v L_{2}}{g(1+\delta)^{2}}$.

16 Now we consider regions 1 under water. To calculate the surface, we use (13) with $g$

17 replaced by reduced gravity $g^{\prime}=g\left(\rho_{c}-\rho_{o}\right) / \rho_{c}$ so that

$18 \quad h_{1}^{3}=d_{0}^{3}+\frac{9 v U_{1} x}{g^{\prime}(1+\delta)^{2}}$.

19 The lateral length for region 1 is found setting $h=0$, at $x=-L_{l}$ so

$20 \quad L_{1}=\frac{g^{\prime}(1+\delta)^{2} d_{0}^{3}}{9 U_{1} v}$. 
1 Since we specify $g^{\prime}<<g$, for the purpose of determining a volume of the crust in this

2 region, we approximate $L_{1}=0$.

3 For use in the following section, it is necessary to find the volume of the

4 continent. Assuming that this 2 dimensional model has a typical width $w$ in the third

5 direction, and noting that the total depth of the continent at each point is given by

$6 \quad(1+\delta) h_{i}(x)$, the volume of each region is

$7 \quad V_{1}=0$

$V_{2}=w \int_{0}^{L_{2}}(1+\delta)\left(d_{0}^{3}+\frac{9 U_{2} v x}{g}\right)^{1 / 3} d x$

8

$=\frac{3}{4} w(1+\delta)\left(\frac{9 U_{2} v}{g}\right)^{1 / 3}\left\{\left(L_{2}+\frac{g d_{0}^{3}}{9 U_{1} v}\right)^{4 / 3}-\left(\frac{g d_{0}^{3}}{9 U_{1} v}\right)^{4 / 3}\right\}$

9

$V_{3}=\frac{3}{4} w(1+\delta)\left(\frac{9 U_{3} v}{g}\right)^{1 / 3}$

$\left\{\left(L_{2}+L_{3}+\frac{g(1+\delta)^{2} d_{0}^{3}}{9 U_{3} v}+\frac{\left(U_{2}-U_{3}\right) L_{2}}{9 U_{3}}\right)^{4 / 3}-\left(L_{2}+\frac{g(1+\delta)^{2} d_{0}^{3}}{9 U_{3} v}+\frac{\left(U_{2}-U_{3}\right) L_{2}}{9 U_{3}}\right)^{4 / 3}\right\}$

10 It is convenient to approximate these volumes.

$11 V_{1}=0$.

12 In regions 2 and 3, the elevation is expanded as a Taylor series about the left hand point

13 that starts each region so that

$14 \quad V_{2}=w d_{0}(1+\delta) L_{2}\left\{1+\frac{v U_{2} L_{2}}{6 g(1+\delta)^{2} d_{0}^{3}}\right\}$

$15 \quad V_{3}=w d_{0}(1+\delta) L_{3}\left(1+\frac{v U_{2} L_{2}}{3 g(1+\delta)^{2} d_{0}^{3}}\right)\left(1+\frac{v U_{3} L_{3}}{3 g(1+\delta)^{2} d_{0}^{3}}\right)$

16 To make realistic tabular continents, the term on the right within the brackets in

17 (22) must be small so that the old continent has roughly constant thickness. This is true if

$18 \frac{v U_{2} L_{2}}{6 g(1+\delta)^{2} d_{0}^{3}}<1$. Using present Earth values in mks units of $g=10 \mathrm{~ms}^{-2}, d_{0}=3800 \mathrm{~m}, \rho_{2}$

$19=2800 \mathrm{~kg} / \mathrm{m}^{3}, \rho_{3}=3300 \mathrm{~kg} / \mathrm{m}^{3}$, and $L_{2}=10^{7} \mathrm{~m}$, this requires that $v U_{2}<2.5 \times 10^{3}$. If one

20 uses a speed associated with 0.1 times a value for mantle convection of $.3 \times 10^{-9} \mathrm{~ms}^{-1}$ the 
1 continent kinematic viscosity in this model has to be significantly smaller than $22.5 \times 10^{12}$

$2 \mathrm{~m}^{2} \mathrm{~s}^{-1}$. This is a value lower than commonly used mantle viscosity values that are

3 approximately $10^{17} \mathrm{~m}^{2} \mathrm{~s}^{-1}$ (Turcotte and Schubert 2002), but such a small value is

4 appropriate here since it quantifies the effects of erosion. It is similar in magnitude to

5 values of erosion by Zhang (2005) with timescales of $10^{8}$ years, and who used an

6 empirical value for uplift rate of similar magnitude that fits the present continents. The

7 smallness of this viscosity compared to mantle viscosity gives a measure of the strength

8 of erosion needed for Earth to have tabular continents (also discussed by Zhang loc.cit.).

9 This low value suggests that the early experiments in Section 2 and the theory in

10 Appendix 1 might be revisited using lower continent viscosity. However, a layer

11 corresponding to the ocean should also be added. In region 3, one would specify a lateral

12 length perhaps $L_{3}=10^{6} \mathrm{~m}$ with bottom speed 20 times greater.

13 The important result for this model of the continent is that the body is not tabular

14 because of its strength, but because the rate for erosion flattening the continent is greater

15 than the rate of mountain generation. This result is also pointed out by Zhang (loc.cit.).

16 However, we also have added the fact that the ocean imposes a freeboard constraint.

17 Although it can be argued that the freeboard-orogeny-erosion balance applies to earth,

18 supporting this through analysis from data about orogeny in addition to the rates of

19 erosion already quantified by Zhang (loc.cit.) is beyond the scope of this paper.

\section{Transient adjustment}

22 The surface evolution is driven by conservation of volume flux

$23(1+\delta) \frac{\partial h_{i}}{\partial t}=\frac{\partial F_{i}}{\partial x}$,

24 which can be advanced numerically. The timescale is $v / g d_{0}^{2}$, the speed scale is

$25 U_{2} v / g d_{0}^{2}$ and the dimensionless area flux scale is $g d_{0}^{3} / v$. Figure 6 shows a calculation in

26 which there is only one region corresponding to Region 2 with no Region 3. The surface

$27 h$ gradually approaches a slope with a value of $3 \times 10^{-5}$. Note that an initial bump is

28 substantially smoothed out after one time unit. 

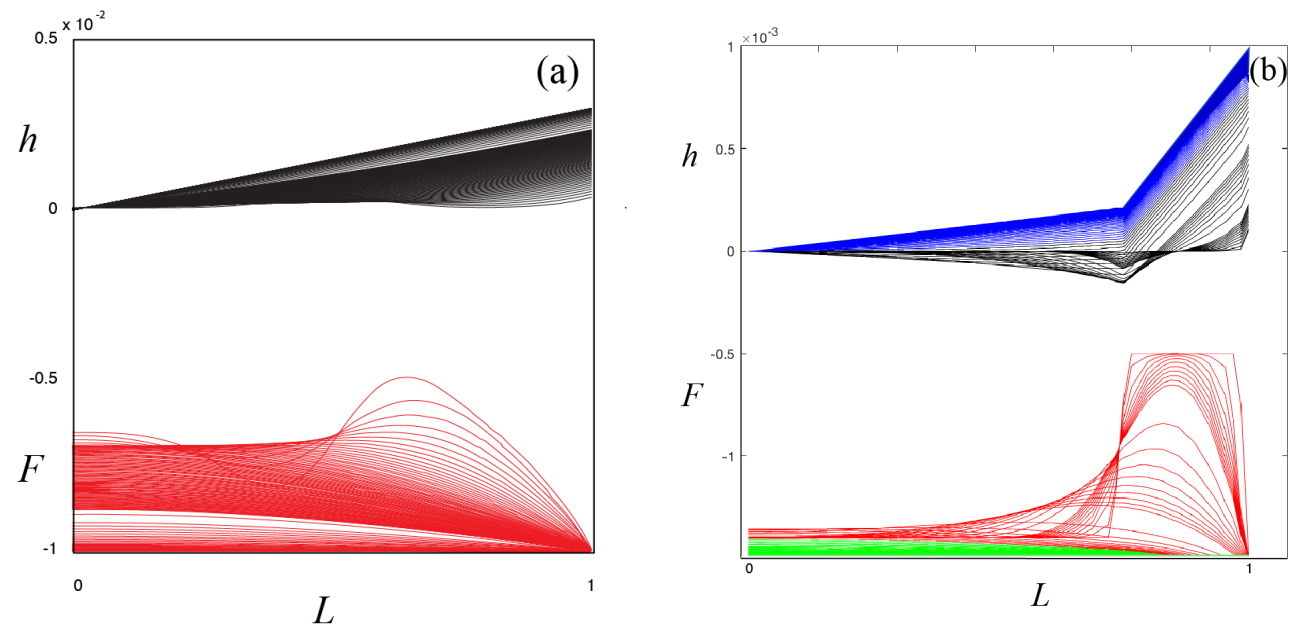

Figure 6. Transient response of surface elevation and flux driven by a moving bottom. (a) Uniform speed $U_{2} v / g d_{c}{ }^{2}=10^{-5}$. A bump that is initially placed in the middle relaxes with time. Elevation values are multiplied by five to show details. Time is normalized by dividing by timescale $\mathrm{v} / g d_{c}$. Time intervals are 0.1 units. A value of $10^{-3}$ is subtracted from flux to offset it from zero. (b) There are different driving speeds in two regions. On the right, the speed is ten times greater. Time intervals are 0.01 units before $t=0.1$, then intervals are 0.1 up to $t=1$, then intervals are 1 (blue/green) up to $\mathrm{t}=4$. Flux $F$ is normalized by dividing by $g d_{c}^{3} / \mathrm{v}$ and a value of $0.15 \times 10^{-3}$ is subtracted to offset it from zero.

\section{4. Areas and thicknesses of ocean and continent}

In section 2 , the experiments essentially had no ocean at all, so $d_{0}=0$. In section 3 ,

14 the ocean depth $d_{0}$ is specified. Here, the value of $d_{0}$ is determined using simple

15 hydrostatic equations. In the previous section, the pressure under the ocean was not a

16 factor in the model. The pressure under the continents was hydrostatic and consistent

17 with lubrication theory. In this section, the ocean lies over Earth's mantle and contributes

18 to pressure in the mantle. The mantle, continent and ocean are not moving and a

19 hydrostatic balance exists between ocean and continent. The cartoon in Figure 7a (taken

20 from Figure 1) shows the factors contributing to the thickness of the continent. The

21 cartoon in Figure $7 \mathrm{~b}$ shows the hydrostatic model analyzed here. The continents are

22 aggregated together as one solid body that is floating on a liquid mantle. It lies next to a

23 motionless liquid ocean. 

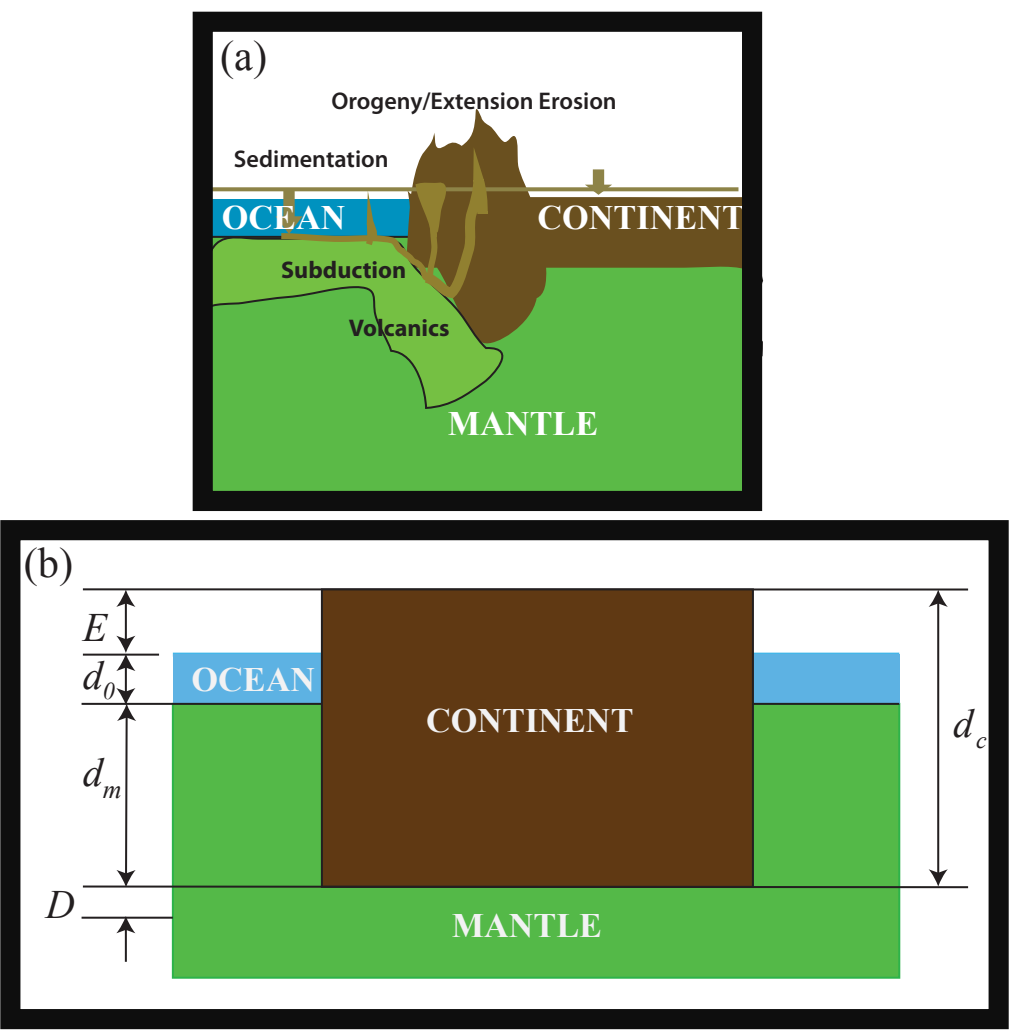

Figure 7. (a) Sketch of the first-order factors modifying the thickness of the continental crust. (b) The hydrostatic balance of ocean basins and continents. (Simplified from Figure 5 in Whitehead and Clift, 2009).

Pressures within the mantle under ocean and continent are calculated using

7 hydrostatics and set equal to each other. Mantle pressure under the oceans equals the

8 weight per unit area from the accumulation of ocean water of depth $d_{o}$ and mantle of

9 thickness $d_{m}$. This is set equal to the weight per unit area under the continents of

10 thickness $d_{c}$ due to the continental crust. Hydrostatic pressure is calculated using the

11 densities of ocean $\left(\rho_{\mathrm{o}}=1030 \mathrm{~kg} \mathrm{~m}^{-3}\right)$, continent $\left(\rho_{\mathrm{c}}=2800 \mathrm{~kg} \mathrm{~m}^{-3}\right)$, and mantle $\left(\rho_{\mathrm{m}}\right.$

$12=3300 \mathrm{~kg} \mathrm{~m}^{-3}$ ). The equality of pressure under ocean and continent obeys the formula

$132800 g d_{c}=1030 g d_{o}+3300 g d_{m}+3300 g D$

14 with $g$ the acceleration of gravity. The constant $D$ is added to the equation to correct for

15 everything left out of this model. The list of possible causes of corrections is long and

16 includes many layers in the ocean floor, within the continents and in the upper mantle as

17 well as features of mantle convection and even the density of air.

18 Defining $E$ as the elevation of the continent above sea level, and using the relation

$19 E+d_{o}+d_{m}=d_{c}$ to eliminate $d_{m}$ from $(25)$, 


$$
1 \quad E=\frac{3300-2800}{3300} d_{c}-\frac{3300-1030}{3300} d_{0}+D .
$$

2 Next, the known values of the volumes of continental crust and water are incorporated.

3 Using volume $V$, area $A$ and the subscript $o$ for ocean, and $c$ for continent, where

$4 d_{c}=V_{c} / A_{c}$

5 and

$6 d_{o}=V_{o} / A_{o}$

7 Using the fact that the two areas add up to the surface area of Earth

$8 A_{o}+A_{c}=510 \times 10^{6} \mathrm{~km}^{2}$

$9 \quad A_{o}$ is eliminated using (28) and (29) and (26) becomes

$10 E=\frac{500}{3300} d_{c}-\frac{2270 V_{0} d_{c}}{3300\left(5.1 \times 10^{8} d_{c}-V_{c}\right)}$

11 This reduces to the quadratic equation for crust thickness

$122.55 \times 10^{11} d_{c}^{2}-\left(500 V_{c}+2270 V_{o}-1.683 \times 10^{12}(D-E)\right) d_{c}-3300 V_{c}(D-E)=0$

13 with solution

$14 d_{c}=F \pm \sqrt{F^{2}+1.294 \times 10^{-8} V_{c}(D-E)}$

15 where $F=\left(500 V_{c}+2270 V_{o}-1.683 \times 10^{12}(D-E)\right) / 5.10 \times 10^{11}$.

16 Does (32) produce a reasonable prediction of depth of continental crust on Earth

17 as a function of water and crust volumes? First, we ignore all deviations between this

18 model and Earth by setting $D=0$ and using the values $V_{c}=7.679 \times 10^{9} \mathrm{~km}^{3}$ and

$19 V_{o}=1.178 \times 10^{9}$ [Whitehead and Clift 2009]. Using the present value of continent

20 elevation above the sea surface $E=0.835 \mathrm{~km}$ [Turcotte and Schubert 2002] in equation

21 (32), we get $d_{c}=28.1 \mathrm{~km}$. This depth is $73 \%$ of the present average crust thickness $d_{c}=$

$2238.4 \mathrm{~km}$, [Whitehead and Clift 2009]. Continent area using this thickness and the present

23 volume of crust is $2.67 \times 10^{8} \mathrm{~km}^{2}$, which is $133 \%$ of the actual area of $2 \times 10^{8} \mathrm{~km}^{2}$.

24 Consequent ocean area is $2.53 \times 10^{8} \mathrm{~km}^{2}$, which is $81 \%$ of the actual area of $3.10 \times 10^{8} \mathrm{~km}^{2}$.

25 The fact that all these values are within $34 \%$ of earth's values indicates that this

26 extremely crude model is a good first approximation.

27 It is clear that secular changes in the value of $D$ might arise, for example from

28 secular changes in heat flow (Schubert and Reymer 1985). It is not the object here to 
1 determine a better value of the present value of $D$ from direct geophysical measurements

2 (e.g. Gossler and Kind 1996), although that would make a useful future study. Instead,

3 we use the present crust thickness $d_{c}=38.4$ to calculate the value of $D$ for present Earth

4 and it is $D=-2.369 \mathrm{~km}$. Naturally, using (26) with this value of $D$ gives the present value

5 of ocean depth $d_{o}=3.8 \mathrm{~km}$ [Whitehead and Clift 2009] as well as the correct ocean and

6 continent areas.

It is useful to insert $D=-2.369 \mathrm{~km}$ in (32) and find possible thicknesses and areas

8 for earlier earth by considering plausible ranges of volumes of early continental crust and

9 water. Here Earth's present area is used. In addition, since early erosion is not easily

10 quantified, a number of values of $E$ [Müller et al. 2008] are considered. Figure 8a shows

11 the continental crust thickness as a function of $V_{c}$ for assorted values of $E$ using the

12 present day value of $D$ and the present ocean volume (a value consistent with the present

13 ocean area $A_{o}=310 \times 10^{6} \mathrm{~km}^{2}$, and ocean depth $d_{o}=3.8$ [Whitehead and Clift 2009]. Values

14 of ocean depth (Figure 8b) can also be found since it is linearly related to crust thickness

15 by (26). The curves are the same as those in 8 a but with different offset.

16
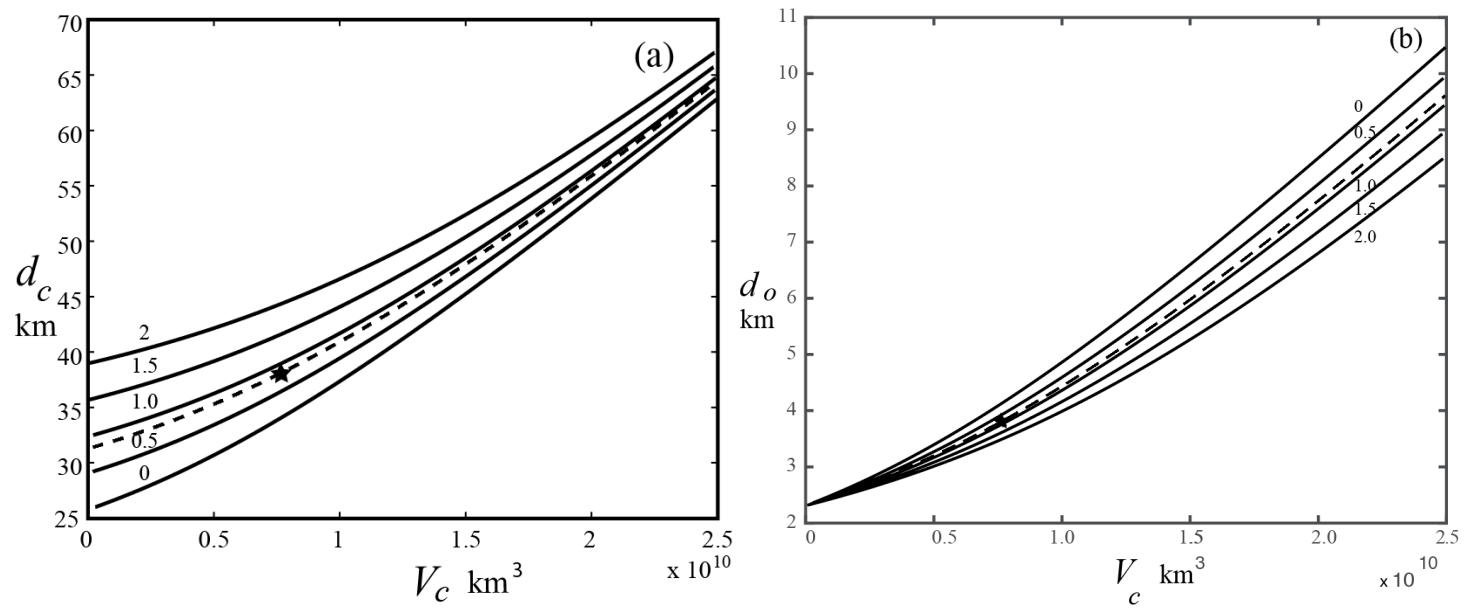

Figure 8. (a) Thickness of the continental crust as a function of continental crust volume using (32). The solid curves are for 5 different values of mean continent elevation above sea level $E$ (in $\mathrm{km}$ ) and the sixth with present elevation $E=0.835 \mathrm{~km}$ is shown as a dashed curve. The star shows present Earth. (b) Ocean depth using (26). Water volume is fixed at the present value $V_{o}=1.178 \times 10^{9} \mathrm{~km}^{3}$ and $D=-2.369 \mathrm{~km}$.

Figure 8 shows a number of things: First, $d_{c}$ extends from approximately 25 to 66 $\mathrm{km}$ in thickness. Second, the spread of the curves for different values of $E$ means that 
1 continent thickness is sensitive in detail to continent elevation and hence, presumably to

2 erosion rate. Third, since $E$ and $D$ are subtracted in equation (32), thickness is also

3 sensitive to the exact value of $D$. Therefore, if early continent or mantle structures differ

4 significantly from their present structures, the effect would be similar to the effects of

5 different levels of erosion. Fourth, ocean depth varies considerably because $d_{o}$ ranges

6 from just over $2 \mathrm{~km}$ up to almost $11 \mathrm{~km}$. Since (26) shows that $d_{0}$ is linearly proportional

7 to $d_{c}$, the curves in (a) and (b) have the same shape even though relative offsets are

8 different. Fifth, and most importantly, even with this wide range of $E$ (hence $D$ ),

9 continental crust thickness never is less than $25 \mathrm{~km}$. The result that crustal thickness

10 exceeds a certain value is consistent with the fact that the crust of cratons has thicknesses

11 of the order of present crust (King 2005), resulting in cratons covering a significant part

12 of the present continents (Figure 9).
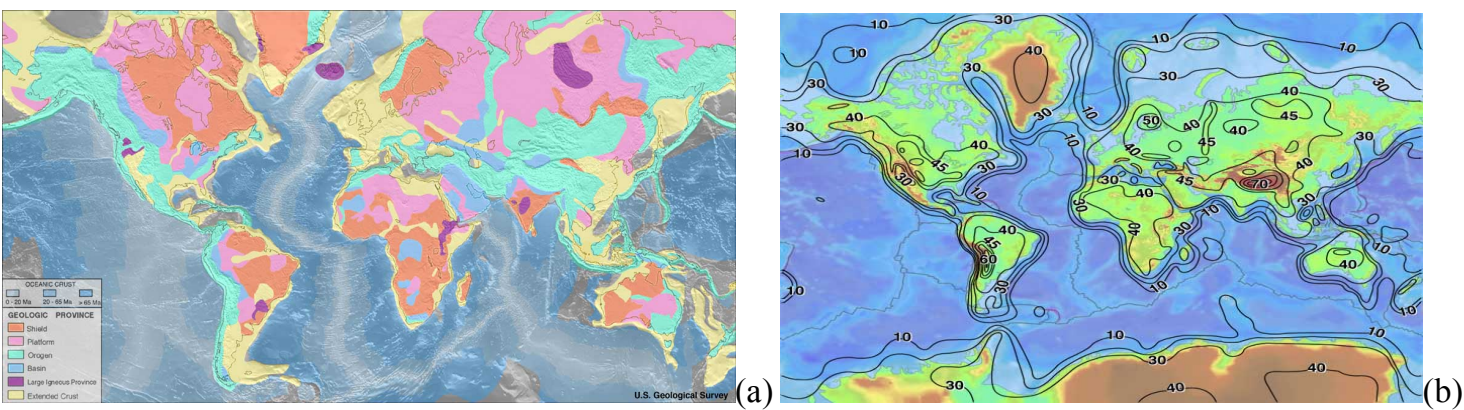

14 Figure 9. (a) Map of geological provinces of the world. The shields are cratons extending to the surface and the platforms are cratons covered with sediment. (From public domain by USGS - http://earthquake.usgs.gov/data/crust/maps.php). (b) Continental crust thickness (km). (From public domain by USGS -

Figure 10 shows results for the same parameters as used to make Figure 8 plotted against areas. First, we see again $d_{c}<25 \mathrm{~km}$. Second, continent area extends up to approximately

$2380 \%$ of the total area of earth in the limit of three times the present crust volume. Third,

24 ocean area correspondingly is as small as $20 \%$ in the same limit. Fourth, very small

25 values of $V_{c}$ result in vanishing continent area so that Earth is largely covered by water.

26 Fifth, present Earth (stars) is in a region sensitive to changes so relative thickness and

27 areas change with different volumes of materials and erosion rates. Summarizing the 
1 results shown in Figures 8 and 10, continent crustal thickness is likely to range between

2 the extremes of 25 to $70 \mathrm{~km}$, but for all crust volumes, continent area is less than $80 \%$ of 3 earth's area and the ocean area is more than $20 \%$.
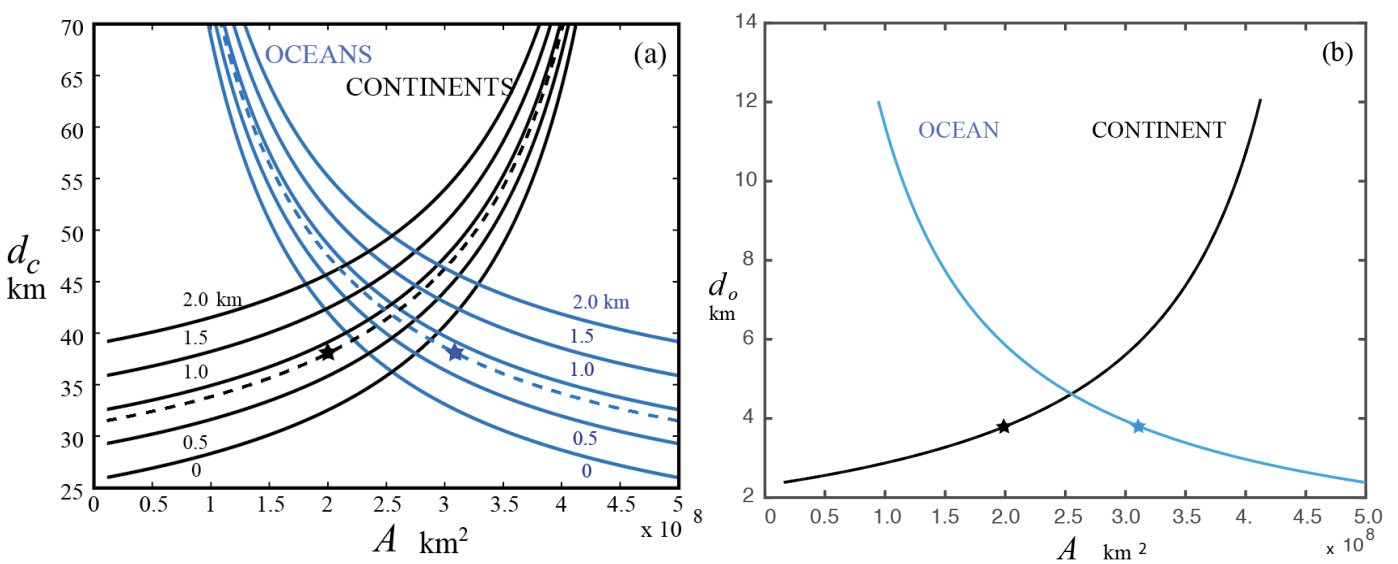

Figure 10. (a) Continent thickness as a function of the areas of the continents and oceans. Solid curves are for 5 different values of mean continent elevation above sea level $E$ and the sixth dashed curve is for present elevation. (b) Ocean depth versus areas of the continents and oceans collapses to a single curve for all $E$. Water volume is fixed at the present value $V_{o}=1.178 \times 10^{9} \mathrm{~km}^{3}$ and $D=-2.369 \mathrm{~km}$.

Next, we investigate sensitivity of continent crust thickness and ocean depth to

12 the volume of planetary water $V_{o}$. Since past values are poorly constrained, a wide range

13 of values of water volume from 0.01 to 10 times the present volume is used. Mean

14 continent elevation is set to the present value $E=0.835 \mathrm{~km}$. Figure 11 shows crust

15 thickness as a function of crust volume and areas. Crust thickness extends from $23.4 \mathrm{~km}$

16 to almost $180 \mathrm{k}$. Figure 12 shows ocean depth. It ranges from almost zero to $35 \mathrm{~km}$.

17
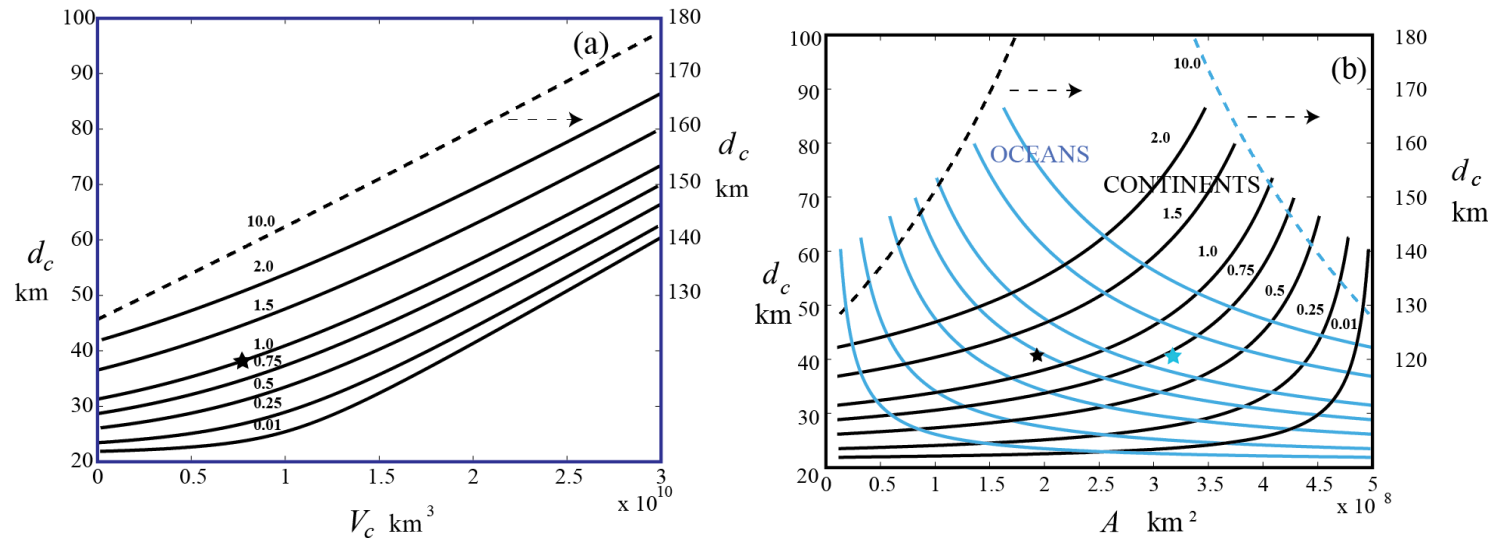
Figure 11. Continental crust thickness for 8 values of the ratio of water volume to the present value as a function of (a) continental crust volume and (b) areas of oceans and continents (the dashed lines are offset from the solid lines and they use the scale shown on the right). The stars show present Earth. $E=0.835 \mathrm{~km}$ and $D=-2.369 \mathrm{~km}$.
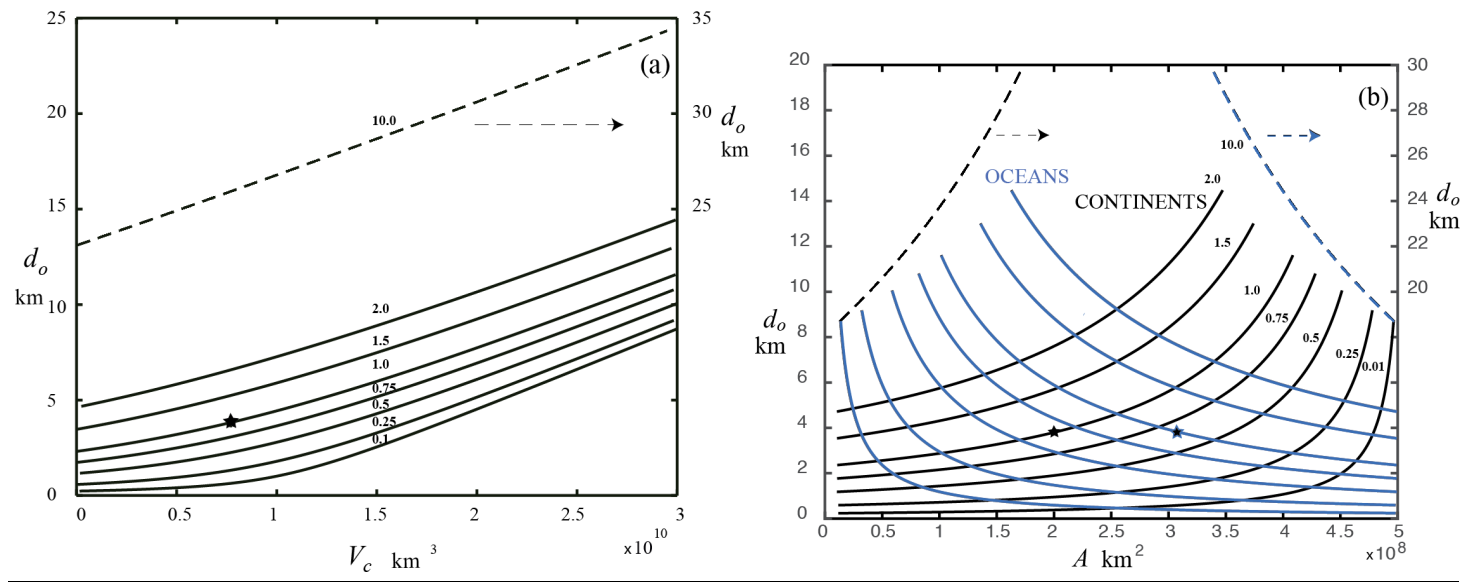

Figure 12. As in Figure 11 but for ocean depth instead of crust thickness.

In summary, the analysis in this section shows that continental crust is greater than about $22 \mathrm{~km}$ (Figures 8, 10, 11, and 12). With present water volume on Earth, continents occupy less than about $75 \%$ of Earth's area, and oceans occupy more than $25 \%$ of the surface area. These results assume first that there are circumstances where continents have evolved long enough for the dynamic balance described here to have become established on earth. Second, it assumes Earth has similar material properties and weathering rates so that erosion is strong enough to limits the elevation of the continent material. Third, it assumes similar values of $D$.

\section{Summary}

Floating oil thickens when subjected to convergence by an underlying fluid, but it thickens with convergence speed and thus has shortcomings as a model of continents on earth. A theoretical fluid model using an ocean layer of given thickness and Newtonian viscosity produces a tabular continent. Using the hydrostatic pressure balance under the continents and ocean basins and using the fact that the average continent surface elevation is less than $1 \mathrm{~km}$ above the ocean surface, calculations show that the average thicknesses and the areas of Earth's continents and oceans are readily estimated as a 
1 function of volumes of continental crust and water. For application to earlier earth, and

2 for almost all possible volumes, the continental crust exceeds $22 \mathrm{~km}$ in thickness and

3 total continent area is less than $75 \%$ of Earth's surface. This constraint may be useful to

4 those studying the evolution of Earth. If suitable changes in surface area are made,

5 calculations may also be useful for other earthlike planets or moons.

Admittedly, the kinetic details and consequences from erosion are crudely

7 represented in the simplified model in section 3. This does not seem to matter because if

8 erosion is strong enough to level mountains in a fraction of a planet's lifetime, the tabular

9 nature of continents is not sensitive to erosion rates. Our model poorly represents other

10 aspects of erosion, too. Material is not swept off the top of the continents, moved to the

11 oceans or to low regions of a continent and swept into the mantle at subduction zones

12 only to be partially returned by volcanism in this model. However, even though this

13 model does not produce a realistic cycle of mantle material from surface to mantle and

14 back, a statement of conservation of the total continent material at any one time plus the

15 conservation of water on the planet is used to determine areas and average thickness of

16 oceans and continents.

17 The theory in Section 3 shows that that tabular continents arise from the simple

18 balance between orogeny, erosion and freeboard. This balance is likely to exist over wide

19 ranges of governing parameters with predictable thicknesses and areas of ocean and

20 continental crust linked to volumes of continental crust and water. In the process, water

21 on Earth, through the act of erosion on land, (and water on any other earthlike planet) has

22 carved its own cistern. This cistern, the ocean, holds most all of the water and causes

23 orogeny and erosion on the continents to form tabular continents. Note also that the

24 tabular nature of continents certainly has effects on the collision and breaking apart of the

25 individual continents during Wilson cycles. Therefore, Earth's water exerts a first order

26 effect on the areas of continents and oceans and presumably thereby it affects the pattern

27 of mantle circulation throughout all the depth of the mantle possibly all the way to the 28 core.

29

30 Acknowledgements 
Conversations with many of the participants of the Woods Hole Oceanographic

2 Geodynamics program stimulated this study. I particularly thank Stan Hart, Peter Molnar,

3 and Peter Clift for useful suggestions over the course of the work.

\section{Appendix The deflection of a crustal layer by mantle circulation}

This two-layer calculation gives the amount of thickening and thinning of floating

9 fluid from circulation of fluid below in the limit of large viscosity (Whitehead 2003). A

10 layer of viscous fluid representing continental crust lies above a circulating mantle. The

11 top layer (Figure A1) has viscosity, $\mu_{1}$ density $\rho_{1}$ and average thickness $d$. It lies above

12 the "mantle" fluid with viscosity $\mu_{2}$ density $\rho_{2}$, and average depth $D_{m}$ in a field of

13 gravity $g$. Simplifications are: 1. Only steady flows are considered. 2. The matching

14 conditions between layers are applied at the level mean interfaces so that the equations

15 are linear. 3. The flows exist for small Reynolds number so that inertial forces are much

16 smaller than viscous forces. 4. The flow is two-dimensional.

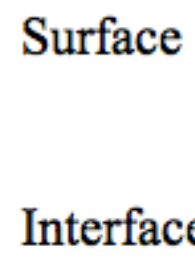

Figure A1. The two layer model driven by velocity at the lower boundary.
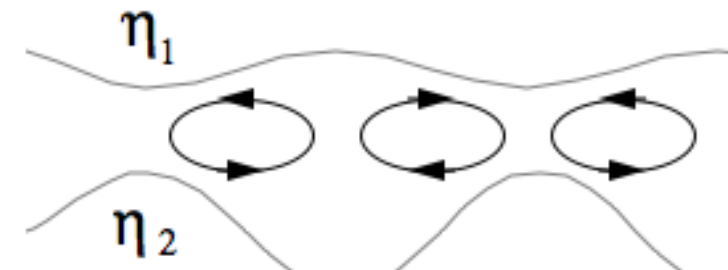

"CONTINENT" Upper Layer

"MANTLE"

Lower

Layer

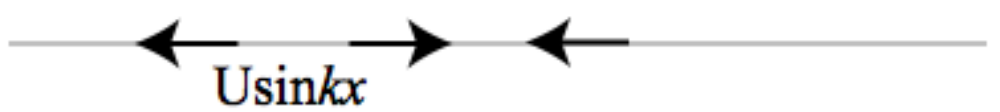

Accordingly, the equations of two-dimensional viscous flow are used

$$
0=-\nabla p_{i}+\mu_{i} \nabla^{2} \tilde{u}_{i}
$$


1 where $i=1,2$ denote the top and bottom layers, respectively, with $\tilde{u}_{i}=u_{i} \hat{i}+w_{i} \hat{j}$ and the

$2 \hat{i}$ and $\hat{j}$ unit vectors in the horizontal and vertical directions. The continuity equation is

$$
\frac{\partial u_{i}}{\partial x}+\frac{\partial w_{i}}{\partial z}=0
$$

4 The boundary conditions at the interface between the two layers (which is taken to be at

$5 z=0$ ) are the matching of lateral velocity $u_{1}=u_{2}$ vertical velocity $w_{l}=w_{2}$, and lateral stress

$6 \quad \mu_{1}\left(\frac{\partial u_{1}}{\partial z}+\frac{\partial w_{1}}{\partial x}\right)=\mu_{2}\left(\frac{\partial u_{2}}{\partial z}+\frac{\partial w_{2}}{\partial x}\right)$

7 In addition, the condition of vertical stress determines a value for interface deflection $\eta_{2}$.

$8 \quad 2 \mu_{1} \frac{\partial u_{1}}{\partial x}+P_{1}-2 \mu_{2} \frac{\partial u_{2}}{\partial x}-P_{2}=g\left(\rho_{2}-\rho_{1}\right) \eta_{2}$

9 Boundary conditions on the top of the upper layer are applied at $z=d$. These conditions

10 are zero vertical velocity, zero lateral stress (often called free-slip), and zero vertical

11 stress that will produce a value for $\eta_{1}$. The final two boundary conditions are imposed at

12 the bottom of the deep layer at $z=-D_{m}$. They are that the vertical velocity is equal to zero,

13 that $w_{2}=0$, and that the imposed velocity $u_{2}=U \sin k x$.

14 The solutions are of the form

$15 w_{i}=\left\{A_{i} \sinh k z+B_{i} z \sinh k z+C_{i} z \cosh k z\right\} \cos k x$.

16 The boundary and interface conditions can be expressed as the matrix equation

$17 \quad \begin{array}{cccccc}k c D & -s D-k D_{m} c D & c D+k D_{m} s D & 0 & 0 & 0 \\ -s D_{m} & D_{m} s D & -D_{m} c D & 0 & 0 & 0 \\ k & 0 & 1 & -k & 0 & -1 \\ 0 & \mu_{2} & 0 & 0 & -\mu_{1} & 0 \\ 0 & 0 & 0 & s d & d s d & d c d \\ 0 & 0 & 0 & 2 k^{2} s d & 2 k c d+2 k^{2} d s d & 2 k s d+2 k^{2} d c d\end{array}|\times| \begin{aligned} & A_{2} \\ & B_{2} \\ & C_{2} \\ & A_{1} \\ & B_{1} \\ & C_{1}\end{aligned}|=| \begin{aligned} & U k \\ & 0 \\ & 0 \\ & 0 \\ & 0 \\ & 0\end{aligned} \mid$ 
1 where $c D=\cosh k D_{m}, c d=\cosh k d, s D=\sinh k D_{m}$ and $s d=\sinh k d$. The solutions for the

2 constants are

$3 \quad A_{1}=2 U k^{2} l \mu_{2}\left[s D-k D_{m} c d\right] /$ Det

$4 \quad B_{1}=2 U k^{2} \mu_{2}\left[s D-k D_{m} c D\right](s d)^{2} / D e t$

$5 \quad C_{1}=-2 U k^{2} \mu_{2}\left[s D-k D_{m} c d\right] s d c d / D e t$

$6 \quad A_{2}=2 U k^{2}\left[\mu_{1} D_{m} s D(s d)^{2}+\mu_{2} D_{m} c D(-k d+s d c d)\right] / D e t$

$7 \quad B_{2}=2 U k^{2}\left[\mu_{1}\left(s D-k D_{m} c D\right)(s d)^{2}\right] /$ Det

$8 \quad C_{2}=2 U k^{2}\left[-\mu_{1} k D_{m} s D(s d)^{2}+\mu_{2} s D(k d-s d c d)\right] / D e t$

9 where

$10 D e t=-2 k \mu_{1}\left[(s D)^{2}-k^{2} D_{m}^{2}\right](s d)^{2}+2 k \mu_{2}\left[s D c D-k D_{m}\right][k d-s d c d]$.

11 The solution for $\eta_{1}$ gives values of the elevation of the surface corresponding to

12 continent elevation

$13 \frac{\eta_{1}}{d}=\eta_{01} \frac{\left[k D_{m} \cosh k D_{m}-\sinh k D_{m}\right][2 k d \cosh k d-3 \sinh k d]}{\left[\sinh ^{2} k D_{m}-k^{2} D_{m}^{2}\right] \sinh ^{2} k d+\mu_{0}\left[\sinh k D_{m} \cosh k D_{m}-k D_{m}\right][\sinh k d \cosh k d-k d]}$

15 where $\eta_{01}=\frac{2 U k^{2} \mu_{2}}{g \rho_{1}}$ and $\mu_{0}=\mu_{2} / \mu_{1}$. The solution for $\eta_{2}$ gives the depth of the

16 deflection of the interface between the two fluids corresponding to "continental roots"

$17 \frac{\eta_{2}}{d}=\eta_{02} \frac{\left[k D_{m} \cosh k D_{m}-\sinh k D_{m}\right]+\lambda \sinh k D_{m} \sinh ^{2} k d+\mu_{0} \lambda \cosh k D_{m}[\sinh k d \cosh k d-k d]}{\left[\sinh ^{2} k D_{m}-k^{2} D_{m}^{2}\right] \sinh ^{2} k d+\mu_{0}\left[\sinh k D_{m} \cosh k D_{m}-k D_{m}\right][\sinh k d \cosh k d-k d]}$

19 where $\eta_{02}=\frac{2 U k^{2} \mu_{2}}{g\left(\rho_{2}-\rho_{1}\right)}$ and $\lambda=D_{m} / d$. 
Since continental crust is very thin compared to the depth of the mantle we take

$2 k d$ small in (A6) and (A7) and also take the crust to be more viscous than the mantle

3 (England and Molner 1997), so $\mu_{0}=\mu_{2} / \mu_{1} \ll 1$. Then, (A6) (A7) simplify to

4

5

9 balance buoyant restoring forces produced by topography. Therefore, this simplified

10 model of the production of continent by mantle convergence does not depend on the

11 viscosity of the continents, or if continent viscosity is a proxy for a very small value of

12 erosion, it does not depend on the strength of erosion.

14 and A7 and for equations (A8) and (A9). For this calculation, the velocity $U=3 \times 10^{-9} \mathrm{~ms}^{-}$

$15{ }^{1}$ was used, which is the spreading rate of the Pacific plate. This model therefore has the

16 same magnitude for the flow speeds in the deep and top shallow mantle, which is

17 appropriate for uniform viscosity mantle convection. The other parameters used are the

18 acceleration of gravity $g=9.8 \mathrm{~ms}^{-2}$, density difference between mantle and continent with

19 the typical value $\rho_{2}-\rho_{1}=600 \mathrm{~kg} / \mathrm{m}^{3}$, and upper layer thickness $d=15 \mathrm{~km}$. This is the

20 value if all continental crust were spread evenly over the globe. This calculation is an

21 estimate of what happens in two cases, first, before the continent material is segregated

22 into lumps and second, what happens in the experiments in Figure 2. Panel (a) has the 
1 results for whole mantle convection with $D_{m}=2880 \mathrm{~km}$. The viscosity used is the well-

2 known value for deep mantle convection $10^{21}$ pa-s. The ratio of viscosity between the

3 lower and upper layer are $\mu_{0}=0.01$ and 100 in equations (A6) for the surface and (A7)

4 for the interface (long and short dashes, respectively). In addition, curves from equations

5 (A8) and (A9) are plotted as solid curve and they lie very close to the curve for

$6 \mu_{0}=0.01$, so that excellent agreement exists between the general formulas and the

7 approximations. Generally speaking, the value of the viscosity of the upper layer is not

8 important as long as viscosity is more than ten times greater than mantle viscosity.

9 For parameters with the deflection of order one, the layer would break up and the

10 calculation is invalid. Panel (a) indicates that cells with wavelength greater than about

$116000 \mathrm{~km}$ produce interface deflections indicating break up (thick grey line). Therefore, in

12 this model, continental crust could not cover earth but would instead be broken up into

13 lumps of individual continent. Panel (a) also shows that wavelengths shorter than about

$145000 \mathrm{~km}$ would not form proto-continent, but longer wavelengths produce a bottom

15 interface amplitude of order one.

16 The size of deflection for parameters associated with shallow mantle convection

17 (mantle layer $600 \mathrm{~km}$ deep and viscosity of $10^{19}$ pa s) are shown in figure A2b. The

18 break-up criterion is not found since the amplitude is not close to one even for the longest

19 wavelength mantle motion. 


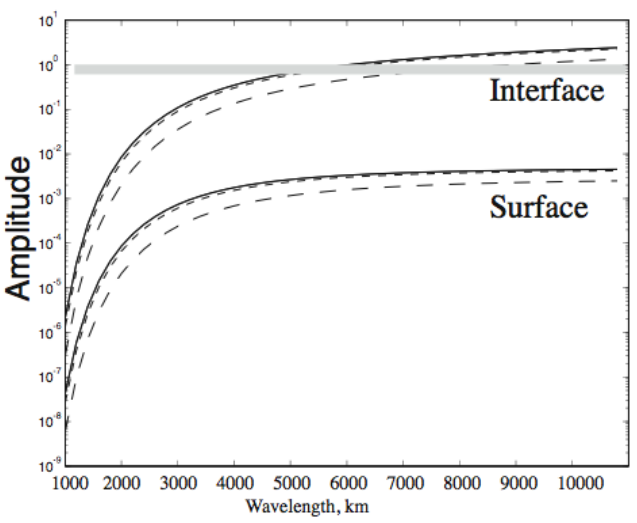

(a)

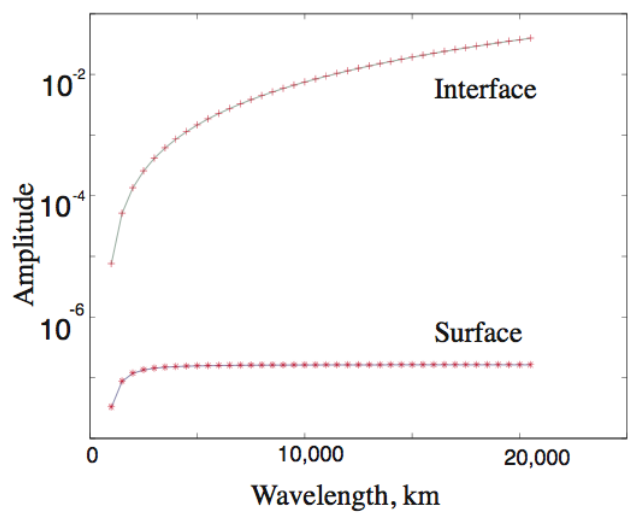

(b)

Figure A2 Elevation of the surface of the top layer and the interface between the two layers as a function of the driving wavelength (a) Results for a deep mantle flow. The long dashed lines are for $\mu_{0}=10^{2}$ the short dashed lines are for $\mu_{0}=10^{-2}$ and the solid lines are for equations (A1) and (A2). The thick grey line indicates the order one amplitude limit of the calculation. (b). Results for shallow lower layer. The symbols are from the approximations in equations (A1) and (A2) and the solid curves from equations (A6) and (A7).

A close view of the velocity field using parameters for both the crust and mantle with $\mu_{0}=10$ is shown in Figure A3. The upper panel has stretched vertical coordinates and a different velocity axis scale than the lower panel. The predominant stress exerted by the lower layer onto the upper layer is from shear $\mu_{2}\left[\frac{\partial u_{2}}{\partial z}\right]$ (the boundary condition $w=0$ imposes the stress component $\mu_{2}\left[\frac{\partial w_{2}}{\partial x}\right]=0$ ). The shear imposed by the lower layer drives a flow in the upper layer that has a return flow near the surface driven by the surface elevation slope. The overturning cell in the top layer is opposite in sense from the overturning cell in the lower layer. The shear exerted by the bottom circulation is almost completely balanced by the surface elevation slope so that the surface elevation slope is not a function of the viscosity of the upper layer. The balance between surface elevation and stress at the base of the surface layer might also be true for mountain belts over a convecting mantle and thus used to estimate shear stress that the mantle exerts on the bottom of mountain belt. The stress induced by surface slope has been used in 
1 conjunction with Global positioning data of divergence to estimate an equivalent

2 viscosity for the Himalayas (England and Molnar 1997).

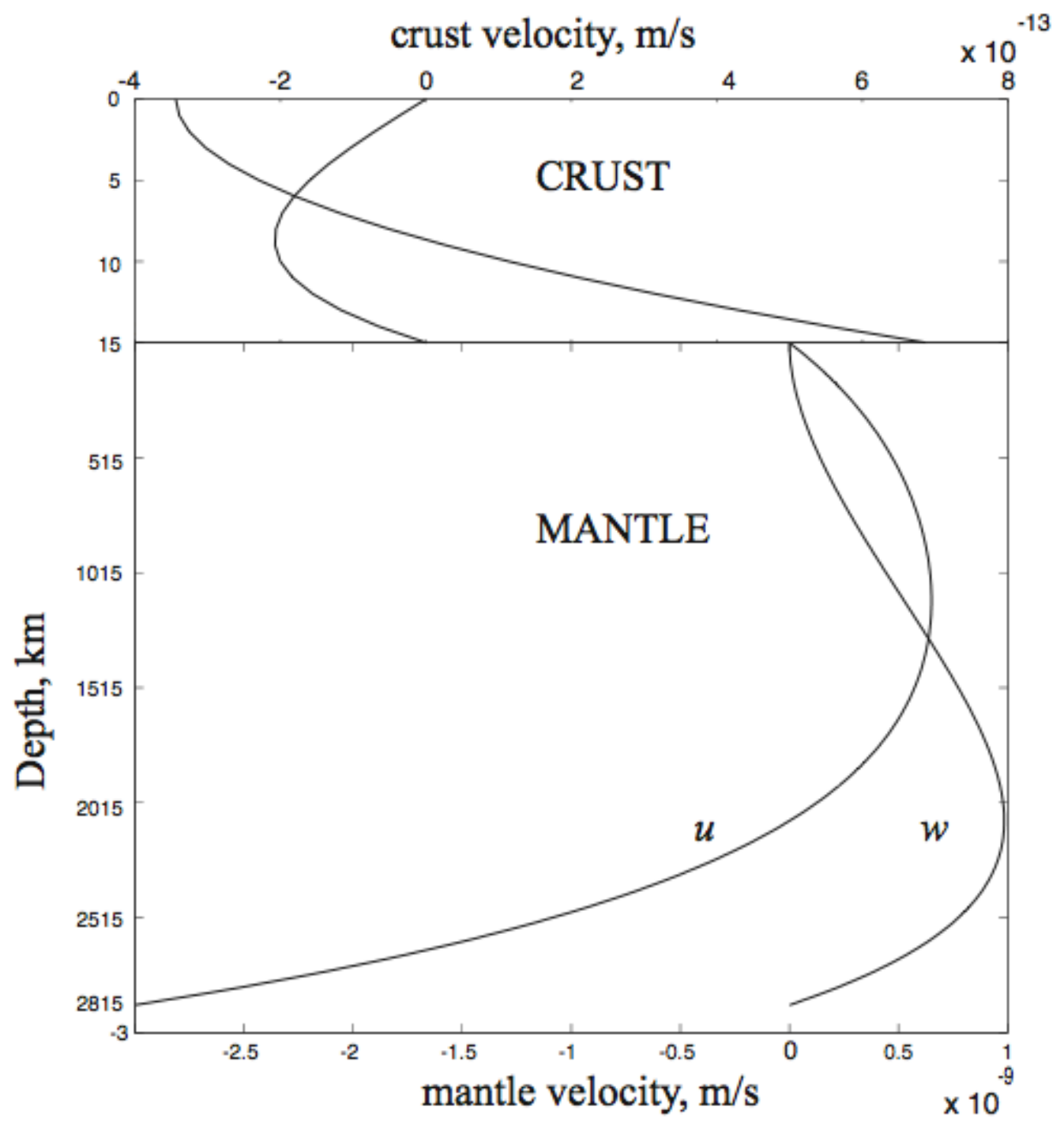

4 Figure A3. Lateral and vertical velocity profiles.

5

6 Finally this is applied to the roller experiment shown in Fig. 3 using (A8) and

7 (A9) and simplifying near the origin

$8 \quad \eta_{1}=\frac{3 U \mu}{2 \rho_{1} g D_{m}}$

9 and for the surface between oil and syrup 


$$
1 \quad \eta_{2}=\frac{3 U \mu}{2\left(\rho_{2}-\rho_{1}\right) g d^{2} k}
$$

4 We use velocity given by $U=2 \pi \Omega$, and the following physical values: syrup density $\rho_{2}$

$5=1439 \mathrm{~kg} / \mathrm{m}^{3}$, silicon oil density $\rho_{1}=1020 \mathrm{~kg} / \mathrm{m}^{3}$, syrup viscosity $32.3 \mathrm{~Pa}-\mathrm{s}$, with roller

6 radius $r=0.018 \mathrm{~m}$, depth between rollers and the oil/syrup interface $d=0.04 \mathrm{~m}$, and

7 wavenumber $k=39 \mathrm{~m}^{-1}$ to get, in meters

$$
\begin{array}{ll}
8 & \eta_{1}=1.36 \times 10^{-3} \Omega \\
9 & \\
& \text { and } \\
10 & \\
11 & \eta_{2}=3.31 \times 10^{-3} \Omega .
\end{array}
$$

These are shown as dashed curves in Figure 3.

\section{References}

Bird, P. (1979), Continental delamination and the Colorado Plateau, J. Geophys. Res., 84, (B13), 7561-7571.

18 Clift, P. D. and P. Vannuchi (2004), Controls on Tectonic Accretion versus Erosion in Subduction Zones: Implications for the Origin and Recycling of the Continental Crust, Reviews of Geophysics 42 (RG2001). Bibcode:2004RvGeo..42.2001C.

22 Clift, P. D., P. Vannucchi, and J. P. Morgan (2009), Crustal redistribution, crust-mantle recycling and Phanerozoic evolution of the continental crust, Earth-Science Reviews 97 (1), 80-104.

25 Cogley, J. G. (1984), Continental Margins and the Extent and Number of Continents, Reviews of Geophysics 22 (2), 101-122. Bibcode:1984RvGSP..22..101C. doi:10.1029/RG022i002p00101. 
1 Condie, Kent C. (2016), The earth as an evolving planetary system, Academic Press,

3 Conrad, C. P., and P. Molnar (1997), The growth of Rayleigh-Taylor-type instabilities in 4 the lithosphere for various rheological and density structures, Geophys. J. Int., 129, $95-112$.

6 Dewey, J. F., and B. F. Windley (1981), Growth and differentiation of the continental

9 Eriksson, P. G. (1999), Sea level changes and the continental freeboard concept: general principles and application to the Precambrian, Precambrian Research 97 (30 143-

12 England, P., \& P. Molnar (1997), Active deformation of Asia: from kinematics to dynamics, Science, 278 (5338), 647-650.

Flesch, L. M., W. E. Holt, A. J. Haines, and B. Shen-Tu, (2000), Dynamics of the Pacific-North American Plate Boundary in the Western United States, Science, 287, 834-836.

Gazel, E. S. T. E. B. A. N., J. L. Hayes, K. Hoernle, P. Kelemen, E. Everson, W. S. Holbrook, \& G. M. Yogodzinski (2015), Generation of continental crust in oceanic arcs, Nature Geoscience, 8, 321-327.

Gossler, J. and R. Kind (1996), Seismic Evidence for very deep roots of continents, Earth and Planetary Science Letters, 138, 1-13.

20 Grotzinger, J. and T. H. Jordan (2010), Understanding earth. Macmillan, 2010.

21 Harrison, C. G. A., (1988) Eustasy and epeirogeny of continents on time scales between about 1 and $100 \mathrm{~m}$. y., Paleoceanography, 3, 671-684.

23 Harrison, C. G. A. (1994), Rates of continental erosion and mountain building, International Journal of Earth Sciences, 83, 431-447.

25 Harrison, C. G. A., (1990) Longterm eustasy and epeirogeny in continents, in Sea-Level 
Change, Nat. Acad. Press, Washington, D. C., 141-158.

2 Harrison. C. G. A., G. W. Brass, E. Saltzman, J. Sloan, II, J. Southam, and J. M. Whitman, (1981) Sea level variations, global sedimentation rates and the hypsographic curve, Earth Planet. Sci. Lett., 54, 1-16.

5 Harrison. C. G. A., K. J. Miscall, G. W. Brass, E. S. Saltzman, and J. Sloan, II, (1983) Continental hypsography, Tectonics, 2, 357-377.

7 Harrison. C. G. A., G. W. Brass, K. Miskell-Garhardt, and E. Saltzman (1985), Reply, $8 \quad$ Tectonics, 4, 257-262.

9 Harrison, C. G. A. (1998), The hypsography of the ocean floor. Physics and Chemistry of 10 the Earth, 23,761-774.

11 Harrison, C. G. A. (1999), Constraints of ocean volume change since the Archean, Geophys. Res. Lett. 26, 1913-1916.

13 Hawkesworth, C.J., B. Dhuime, A.B. Pietranik, P.A. Cawood, A.I.S. Kemp, A.I.S.; and C.D. Storey (2010), The generation and evolution of the continental crust, Journal of the Geological Society (London) 167: 229-248. doi:10.1144/0016-76492009072.

Höning, D., \& T. Spohn (2016), Continental growth and mantle hydration as intertwined feedback cycles in the thermal evolution of Earth. Physics of the Earth and Planetary Interiors, 255, 27-49.

Houseman, G. A., and P. Molnar (1997), Gravitational (Rayleigh-Taylor) instability of a layer with non-linear viscosity and convective thinning of continental lithosphere, Geophys. J. Int., 128, 125-150.

Huerta, A., L. Royden and K. Hodges (1996), The interdependence of deformational and thermal processes in mountain belts, Science, 273, 637-639.

Huerta, A., L. Royden and K. Hodges (1998), The thermal structure of collisional orogens as a response to accretion, erosion, and radiogenic heating, J. Geophys. Res., 103(B7), 15,287-15,302. 
1 Huerta, A., L. Royden and K. Hodges (1999), The effects of accretion and erosion on the metamorphic evolution of collisional orogens, J. of Metamorp. Geol., 17, 349366.

Hynes, A. (2001), Freeboard revisited: Continental growth, crustal thickness change and Earth's thermal efficiency, Earth Planet. Sci. Lett., 185, 161-172.

Johnson, Michael RW, and Simon L. Harley (2012), Orogenesis: the making of mountains. Cambridge University Press.

Kaufman, P. S. and L. H. Royden (1994), Lower crustal flow in an extensional setting: constraints from the Halloran Hills region, Eastern Mojave Desert, California, J. Geophys. Res., 15,723-15,739.

Kay, R. W., and S. M. Kay (1993), Delamination and delamination magmatism, Tectonophysics, 219, 177-189.

Kearey P., K. A. Klepeis and F. J. Vine (2009), Chapter 10: Orogenic belts”. Global Tectonics (3rd ed.). Wiley-Blackwell. p. 287. ISBN 1-4051-0777-4.

King, Scott D., (2005), Archean cratons and mantle dynamics, Earth and Planetary Science Letters 234.1 1-14.

King, Scott D. Mantle convection, the asthenosphere, and Earth's thermal history (2015) Geological Society of America Special Papers. SPE514-07, 514, $p$

Kuhn, William R., J. C. G. Walker, and Hal G. Marshall (1989), The effect on Earth's surface temperature from variations in rotation rate, continent formation, solar luminosity, and carbon dioxide, J. Geophys. Res. Atmospheres 94.D8 1112911136.

McElroy, B., \& B. Wilkinson, (2005). Climatic control of continental physiography. The 
Journal of geology, 113(1), 47-58.

2 McLennan S. M. \& S. R. Taylor (1983), Continental freeboard, sedimentation rates and growth of continental crust, Nature, 306, 169 - 172, doi:10.1038/306169a0.

4 Müller, R. D., M. Sdrolias, C. Gaina, B. Steinberger, and C. Heine (2008), Long-term sea-level fluctuations driven by ocean basin dynamics, Science, 319, 1357-1362, doi:10.1126/science.1151540.

7 O'Neill, C., A. Lenardic, and K. C. Condie (2015), Earth's punctuated tectonic evolution: cause and effect, Geological Society, London, Special Publications 389.1 17-40.

9 Press, F. (2003), Understanding Earth (4th ed.). Macmillan. pp. 468-469. ISBN 0-71679617-1.

11 Roberts, N.M.W., M. J. van Kranendonk, S. Parman, S. Shirey, P.D. Clift (Eds.) (2015) Continent Formation Through Time, Special Publication, 389, Geological Society, London, doi: 10.1144/SP389.13, 362 pp.

14 Royden, L. (1993a), The evolution of retreating subduction boundaries formed during continental collision, Tectonics, 12, 629-638.

16 Royden, L. (1993b), The tectonic expression of slab pull at continental convergent 17 boundaries, Tectonics, 12, 303-325.

18 Saal, A.L., R. L. Rudnick, G. E. Ravizza, and S. R. Hart (1998), Re-Os isotope evidence 19 for the composition, formation and age of the lower continental crust, Nature $\mathbf{3 9 3}$ (6680): 58-61 doi:10.1038/29966.

21 Schubert, G., \& A. P. S. Reymer (1985). Continental volume and freeboard through 22 geological time. Nature, 316, 336-339. 
1 Schubert, G., and D. Sandwell (1989), Crustal volumes of the continents and of oceanic and continental submarine plateaus, Earth and Planetary Science Letters $\mathbf{9 2 . 2}$ 234-246.

Sverdrup, H. U., M. W. Johnson, and R. H. Fleming (1942), The Oceans: Their physics, chemistry, and general biology. Vol. 7, New York: Prentice-Hall.

Taylor, S.R. and S.M. McLennan (1995). "The geochemical evolution of the continental crust". Rev. Geophys. 33: 241-265. Bibcode:1995RvGeo..33..241T. doi: $10.1029 / 95 R G 00262$.

Thatcher, W., G. R. Foulger, B. R. Julian, J. Svarc, E. Quilty, and G. W. Bawden (1999), Present-day deformation across the Basin and Range Province, Western United States, Science, 283, 1714-1718.

Turcotte D. L., and G. Schubert (2002), Geodynamics, Cambridge University Press, New York, 456 pp.

Uchupi, Elazar, and Kenneth O. Emery (1993), Morphology of the rocky members of the solar system. Springer Science \& Business Media, 1993, 394pp.

Veizer, J., and S. L. Jansen (1985), Basement and sedimentary recycling--2: Time dimension to global tectonics. J. Geol.., 93, 625-643.

Walther, John Victor (2005). Essentials Of Geochemistry. Jones \& Bartlett. p. 35. ISBN $\underline{0-7637-2642-7 .}$

Whitehead, J. A (2003) Laboratory Studies of Mantle Convection with continents and other GFD problems. In: "Recent Research Developments in Fluid Dynamics", Transworld Research Network, Kerala, India.

Whitehead, J. A. and P. D. Clift (2009), Continent Elevation, Mountains, Erosion -- 
$1 \quad$ Freeboard Implications, J. Geophys. Res. B., 114, B05410,

2 doi:10.1029/2008JB006176.

3 Wise, Donald U. (1972), Freeboard of continents through time, Geological Society of

$4 \quad$ America Memoirs 132 87-100.

5 Wise, Donald U. (1974), Continental margins, freeboard and the volumes of continents

6 and oceans through time, The geology of continental margins. Springer Berlin

$7 \quad$ Heidelberg, . 45-58.

8 Yin A., and T. M. Harrison (2000), Geologic evolution of the Himalayan-Tibetan

9 orogens, Annual Review of Earth and Planetary Sciences, 28, 211-280.

10 Zhang, Youxue (2005), Global tectonic and climatic control of mean elevation of

11 continents, and Phanerozoic sea level change, Earth and Planetary Science

$12 \quad$ Letters, 237, 524-531. 